\title{
2007/39
}

Negative intra-group externalities in two-sided markets

Paul Belleflamme and Eric Toulemonde 


\title{
CORE DISCUSSION PAPER
}

$2007 / 39$

\section{Negative intra-group externalities in two-sided markets}

\section{Paul BELLEFLAMME ${ }^{1}$ and Eric TOULEMONDE ${ }^{2}$}

June 2007

\begin{abstract}
Two types of agents interact on a pre-existing free platform. Agents value positively the presence of agents of the other type but may value negatively the presence of agents of their own type. We ask whether a new platform can find fees and subsidies so as to divert agents from the existing platform and make a profit. We show that this might be impossible if intra-group negative externalities are sufficiently (but not too) strong with respect to positive inter-group externalities.
\end{abstract}

Keywords: two-sided markets, naked exclusion, divide and conquer

JEL classification: L11, L13, L23

${ }^{1}$ CORE and IAG-Louvain School of Management, Université catholique de Louvain, Belgium. E-mail: belleflamme@core.ucl.ac.be

${ }_{2}^{2}$ FUNDP-University of Namur and CORE, Université catholique de Louvain, Belgium. E-mail: eric.toulemonde@fundp.ac.be

We are grateful to Rabah Amir, Jean J. Gabszewicz, Georg Kirchsteiger, Yann Ménière, Pierre Picard, Thomas Trégouët and Xavier Wauthy for useful remarks and suggestions on an earlier draft. We also thank seminar participants at Telecom Paris, CE-SIfo, CORE and FUNDP.

This paper presents research results of the Belgian Program on Interuniversity Poles of Attraction initiated by the Belgian State, Prime Minister's Office, Science Policy Programming. The scientific responsibility is assumed by the authors. 


\section{Introduction}

Many economic and social situations require the interaction among different groups of agents and this interaction exhibits both inter- and intra-group externalities: (i) inter-group externalities, or indirect network effects, as far as agents of one group are better off when the number of agents of the other group increases; (ii) intra-group externalities, or competition effects, as far as agents within a group compete with each other. For instance, payment systems organized around credit cards share these characteristics: (i) the more merchants accepting a particular card, the higher the benefits for consumers carrying this card, and vice versa; (ii) merchants compete for the trade of consumers. Similarly, for computer operating systems, (i) users enjoy an OS with a large variety of software, and developers prefer to write software for an OS with a large base of users; (ii) competition exists among developers. Yellow pages, web directories and search engines can also be seen along these lines: both advertisers and users enjoy a large representation of the other group but advertisers compete for eyeballs. And so it goes in other so-called multi-sided markets such as video game consoles, shopping malls, matchmaking services, real estate agents, localized markets, etc (see, e.g., Evans, 2003).

The platforms on which agents interact may, or may not, be run by forprofit intermediaries (Visa and Mastercard vs the cash system, MS-Windows vs Linux, JSTOR vs Google Scholar, ...). The issue we study is whether, and if yes how, a for-profit platform can succeed in an environment where agents have the possibility to interact on a free (public or open) platform. Business strategies of for-profit intermediaries are shaped by inter- and intra-group externalities. In the presence of inter-group externalities, for-profit intermediaries face the following well known difficulty: to increase the willingness to pay of one group, an intermediary needs to raise the participation of the

other group, but he can only do so by lowering the price that he charges to this other group. As Caillaud and Jullien (2003, p. 310) put it: "Due to indirect network effects, the key pricing strategies are of a "divide-and-conquer" nature, subsidizing the participation of one side (divide) and recovering the loss on the other side (conquer)." 
Intra-group externalities, however, blur the picture. Another way to increase the willingness to pay of rival agents is to attract only a few of them. The good news for the intermediary is that it makes the participation of rival agents less dependent on the participation of the other group. The bad news is that the other group is less willing to participate if the intermediary attracts only a few rival agents.

To examine the interplay between the two types of externalities, we build a simple model of interaction between two groups of homogeneous agents. Initially, the two groups interact on a free platform. Then comes a for-profit intermediary who sets fixed membership fees (or subsidies) for agents of both groups in order to attract them on the new platform he has created. We focus on situations where agents of both groups single-home. That is, interactions are platform-specific and affiliation to multiple platforms is not feasible. Among the above examples, localized markets (like flea and farmer markets) correspond well to this description because interaction requires that agents be simultaneously present on the same platform. In other real world environments, single-homing follows from indivisibilities, specific investments and limited resources, or can be seen as a good approximation. For instance, in the video game industry, both developers and gamers have the possibility to multi-home but it turns out that very few of them actually do. ${ }^{1}$ Moreover, restricting the attention to single-homing environments simplifies the analysis and allows us to derive neat and insightful results about the effects of intra-group externalities, which is our main focus.

Results. Our main results are the following. We start with the benchmark case where there are no intra-group externalities. We show that in this case, the intermediary can always find a profitable way to launch the new platform. The appropriate divide-and-conquer strategy consists in subsidizing the group that secures the lowest initial total benefits and to tax the other group. We then examine the effects of having intra-group externalities in one group. One major implication is that intra-group externalities may undermine all attempts to launch the new platform. If intra-group externalities are neither too weak nor too strong with respect to the strength of

\footnotetext{
${ }^{1}$ Clements and Ohashi (2005) report that only $17 \%$ of game titles in their sample are available on multiple platforms.
} 
inter-group externalities, then the intermediary cannot find any profitable way to launch the new platform: all strategies fail (i.e., simultaneous moves of the two groups or sequential moves with either group moving first). On the other hand, if intra-group externalities are weak enough or strong enough, there exist divide-and-conquer strategies allowing the intermediary to make a profit. Noteworthy is the fact that the best divide-and-conquer strategy might lead the intermediary to subsidize the group that initially secures the largest total benefits. All these results are obtained in a very general setting, with minimal restrictions imposed on the benefit functions. To illustrate the general results and to obtain some additional insights, we develop two specific examples, one with linear benefit functions and the other with benefit functions derived as the equilibrium profits of a successive oligopoly model.

Related literature. This paper naturally relates to the recent literature in industrial organization that examines multi-sided markets. Most analyses apply to specific industries: payment systems (Rochet and Tirole, 2002; Wright, 2003 and 2004), the Internet (Caillaud and Jullien, 2003; Baye and Morgan, 2001), video games (Hagiu, 2004), media markets (Ferrando et al., 2004), shopping malls (Nocke et al., 2004), software platforms (Evans et al., 2005). More general approaches are proposed by Rochet and Tirole (2003) and Armstrong (2005). Rochet and Tirole (2005) and Jullien (2005) propose useful road maps to this flourishing literature. The main emphasis of these papers is on the effects of inter-group externalities on the design of pricing structures, the competition between platforms, multihoming vs single-homing decisions, platform ownership, ... Intra-group externalities are either abstracted away or not central to the analysis. ${ }^{2}$ Our contribution to this literature is to propose a systematic account of how the two types of

\footnotetext{
${ }^{2}$ Intra-group externalities are present in the following papers. In the analysis of the credit card payment industry, Rochet and Tirole (2002) consider a setting where merchants compete with one another but cardholders do not. In Nocke et al. (2004), sellers compete on the market for differentiated products, which are sold to independent consumers. In their models of two-sided location choice, Ellison and Fudenberg (2003) and Anderson et al. (2005) mix inter- and intra-group externalities (buyers prefer markets with fewer other buyers and more sellers, sellers have the reverse preferences), but suppose free access to the two alternative markets. There is thus no role for intermediaries, which leaves these two papers outside the literature on two-sided markets.
} 
externalities jointly shape strategies in two-sided markets.

Our analysis also bears a close connection with the mechanism design literature addressing problems with one principal, many agents and multilateral externalities. Segal (2003) provides a major contribution by characterizing the general form of the principal's optimal divide-and-conquer strategy, according to the nature of externalities among agents and according to whether the principal is able (i) to coordinate agents on her preferred equilibrium and/or (ii) to price discriminate. Specific divide-and-conquer strategies may be used by an incumbent firm who attempts to deter entry by writing exclusionary contracts with customers. If the entrant faces a minimum scale of operation, the incumbent may want to "capture" a sufficient number of customers so that dealing with the remaining free customers does not allow the entrant to cover its fixed cost. In that case, the customers signing an exclusionary contract with the incumbent exert a negative externality on the other customers by reducing competition on the market. This practice, known as "naked exclusion", was first analyzed by Rasmusen et al. (1991) and later, more extensively, by Segal and Whinston (2000). ${ }^{3}$ In our setting, the intermediary plays the role of the incumbent firm, offering take-it-or-leave-it contracts to the agents, and the free platform plays the role of the entrant (they both constitute the outside option for the agents). What makes our setting different is its two-sided nature. We also have that the intermediary may succeed in attracting all agents and so, in eliminating the free platform (which is equivalent to deterring entry in Segal and Whinston). But the explanation differs: the intermediary attracts all agents of one group, thereby preventing the free platform to provide benefits to the other group. In other words, the two-sided nature of our setting endogenizes the exogenous minimum scale on which the naked exclusion argument relies. This is the same idea that Doganoglu and Wright (2006) develop in their analysis of exclusive dealing with network effects. They first focus on the framework of a one-sided market, and then extend it to one of a two-sided market. The latter model usefully complements ours by allowing agents to

\footnotetext{
${ }^{3}$ Genicot and Ray (2006) further extend the analysis by allowing the principal to combine simultaneous and sequential offers, and to re-approach agents who refused a first offer.
} 
multihome and both platform owners to set access fees. On the other hand, intra-group externalities are absent in this model.

The rest of the paper is organized as follows. In Section 2 we lay out the model. In Section 3, we analyze the benchmark case without intra-group externalities. Next, we consider the case where intra-group externalities prevail in one of the two groups; we assume that groups make their decisions either sequentially (Section 4) or simultaneously (Section 5). In Section 6, we apply the general analysis of the previous sections to two specific examples (linear benefit functions and a successive oligopoly model). We conclude in Section 7.

\section{The model}

We consider two groups of homogeneous agents, denoted 1 and 2, with respectively $N_{1} \geq 3$ and $N_{2} \geq 3$ agents. ${ }^{4}$ When the game starts, the two groups interact on a platform whose access is supposed to be free. Then, an intermediary considers launching a competing platform. Agents who switch to this new platform can interact only with the agents who have switched along. That is, we preclude multi-homing: no interaction can take place among agents affiliated with different platforms. As a result, the benefits agents derive on a platform depend only on the number of agents who are active on this platform. Formally, we denote by $\pi_{i}^{k}\left(n_{i}, n_{j}\right)$ the gross benefit for an agent of type $i$ from interacting on platform $k$ with $n_{i}$ agents of its own type and $n_{j}$ agents of the other type $(i \neq j \in\{1,2\})$. In what follows, we assume that the platforms are technically equivalent, and we therefore drop the superscript $k$.

We assume that the benefit functions exhibit positive inter-group externalities:

$$
\pi_{1}\left(n_{1}, n_{2}+1\right)>\pi_{1}\left(n_{1}, n_{2}\right) \text { and } \pi_{2}\left(n_{1}+1, n_{2}\right)>\pi_{2}\left(n_{1}, n_{2}\right) .
$$

\footnotetext{
${ }^{4}$ We exclude the cases where $N_{i}=2$ because they bring complications without adding any insight to our analysis. These complications are due to the fact that our model is discrete and that, with $N_{i}=2$, a single agent represents half of her group, which gives her an excessive influence.
} 
The benefit functions may also exhibit negative intra-group externalities:

$$
\pi_{1}\left(n_{1}+1, n_{2}\right) \leq \pi_{1}\left(n_{1}, n_{2}\right) \text { and } \pi_{2}\left(n_{1}, n_{2}+1\right) \leq \pi_{2}\left(n_{1}, n_{2}\right) .
$$

The first effect results from the indirect network externalities usually observed in two-sided markets: more agents on one side of the market increases the utility of agents on the other side of the market. The second effect translates the idea that agents may compete with one another within a particular group and may therefore prefer, all other things being equal, to be on a platform with fewer of their group mates.

The impacts of this second effect, which we broadly refer to as "rivalry", have not been systematically analyzed so far in the literature on two-sided markets. To fill this gap, we introduce rivalry in one of the two groups and contrast with the case where no rivalry is observed. ${ }^{5}$ We carry out this comparisons assuming that the two groups move either sequentially or simultaneously. Sequential switching is a natural assumption in several categories of two-sided markets where most agents of one side of the market arrive before most agents of the other side. For example, Hagiu (2004) points that "in the software and videogame markets, most application developers join platforms (operating systems and game consoles) before most users do." In other industries, however, there is no reason to assume that one group moves before the other. As we will show, the timing of moves becomes relevant in the presence of rivalry. Formally, we contrast the following two games.

- In the sequential switching game, we assume the following order of moves: in stage 1 , the intermediary sets a membership fee $A_{1}$ for agents of group 1 (which corresponds to a fixed registration charge for accessing the new platform). In stage 2 , agents of group 1 simultaneously choose whether to switch to the new platform. In stage 3 , the intermediary sets the membership fee $A_{2}$ for agents of group 2 and in

\footnotetext{
${ }^{5}$ We do not consider the case where rivalry prevails in both groups. As we explain in Appendix 8.3, we cannot characterize the equilibria, as there is no way to balance the effect of the conflicting inter- and intra-group externalities without imposing additional structure on the generic benefit functions.
} 
stage 4, agents of group 2 choose whether to switch to the new platform. Here, in the presence of rivalry, it clearly matters whether the rival group is moving first or second. ${ }^{6}$

- In the simultaneous switching game, there are only two stages: in stage 1 , the intermediary sets the membership fees $A_{1}$ and $A_{2}$; in stage 2 , both groups of agents simultaneously decide whether to switch or not to the new platform.

In all settings, our equilibrium concept is a refinement of subgame perfection. Because of positive network externalities, multiple Nash equilibria in pure strategies can occur in the stages where one group or the other decides to switch. As there is no obvious way to select among these equilibria on some a priori basis, ${ }^{7}$ we require that the intermediary set fees in such a way that a unique (subgame-perfect) Nash equilibrium ensues. In other words, we follow Segal (2003) by imposing unique implementation. ${ }^{8}$

In particular, unique implementation forces the intermediary to choose fees so as to avoid the no-participation equilibrium, which naturally results from the chicken and egg problem common in two-sided markets. ${ }^{9}$ In the noparticipation equilibrium, agents keep their initial benefits, i.e., $\pi_{j}\left(N_{j}, N_{k}\right)$. As it will prove useful in the discussion that follows, we define the high-value group as the group that secures the largest initial total benefits and the lowvalue group as the other group. That is, group $j$ is the high-value group (and group $k$ is the low-value group) if $N_{j} \pi_{j}\left(N_{j}, N_{k}\right)>N_{k} \pi_{k}\left(N_{j}, N_{k}\right)$.

In Sections 3, 4 and 5 we carry out the analysis with generic benefit

\footnotetext{
${ }^{6}$ As our focus is on the impacts of rivalry, we make the simplifying (and quite natural) assumption that the intermediary cannot commit to his fee structure (i.e., he sets the fee for the second group after observing the switching decision of the first group). For an analysis of the possibility of commitment (in the absence of rivalry), see Hagiu (2004).

${ }^{7}$ In general, coexisting equilibria cannot be Pareto-ranked as either the preferences of the groups diverge, or they converge but are at odds with the intermediary's interest.

${ }^{8}$ Owan and Nickerson (2004) and Jullien (2006) also follow Segal (2003). Caillaud and Jullien (2003) use a similar methodology by focusing on equilibria sustained by a "bad-expectation" (or pessimistic) market allocation.

${ }^{9}$ Alternatively, we could say that the intermediary is infinitely risk-averse and therefore adopts a "better safe than sorry" approach by avoiding subgames where a no-participation equilibrium obtains.
} 
functions and derive our main results. Section 6 illustrates the results for two specific benefit functions.

\section{No rivalry}

This is clearly the simplest case. Because the benefits for each agent only depend on the number of agents of the other group with whom she can interact, we write the benefit functions simply as $\pi_{1}\left(n_{2}\right)$ and $\pi_{2}\left(n_{1}\right)$. We solve the sequential and simultaneous games in turn by the method of backward induction. The same result holds in both games: the intermediary adopts a divide-and-conquer strategy which consists in subsidizing the low-value group and taxing away the larger benefits of the high-value group. Although the game is rather simple and the results we obtain are not new (see, e.g., Caillaud and Jullien, 2003), it is useful to detail the solution as it will ease the exposition of the results in the rivalry case.

\subsection{Sequential switching}

The structure of the game implies that the agents in group 2 make their switching decision upon observing the fee set by the intermediary, as well as what the agents of group 1 have decided beforehand. On the other hand, the agents in group 1 are able to rationally anticipate how their decisions will shape the subsequent decisions made by the intermediary and by the agents in group 2.

Consider stage 4 supposing that $n_{1}$ agents of group 1 have moved in stage 2 and that the intermediary set a fee $A_{2}$ in stage 3 . A first immediate result is that we cannot have a Nash equilibrium with $0<n_{2}<N_{2}$ agents of group 2 switching. Indeed, such an equilibrium would require that on both platforms, no agent has an incentive to move to the other platform; that is, we would need that $\pi_{2}\left(n_{1}\right)-A_{2} \geq \pi_{2}\left(N_{1}-n_{1}\right)$ and $\pi_{2}\left(N_{1}-n_{1}\right)>$ $\pi_{2}\left(n_{1}\right)-A_{2}$, which are clearly incompatible. ${ }^{10}$ The intuition is very simple: as agents are identical and have independent payoffs, they all make the same

\footnotetext{
${ }^{10}$ To avoid indeterminacies, we adopt the following tie-breaking rule: if the membership fee makes the agent just indifferent between the two platforms, then the agent chooses the new platform.
} 
decisions. There are thus two potential Nash equilibria: either (i) no agent switches iff $A_{2}>\pi_{2}\left(n_{1}\right)-\pi_{2}\left(N_{1}-n_{1}\right)$, or (ii) all $N_{2}$ agents switch iff $A_{2} \leq \pi_{2}\left(n_{1}\right)-\pi_{2}\left(N_{1}-n_{1}\right)$.

As we use this result repeatedly, we record it formally in the following lemma:

Lemma 1 Suppose group $j$ is non rival and does not move before group $k$. Then all agents of group $j$ make the same switching decision.

In stage 3, the intermediary's objective is to set the highest fee that attracts all $N_{2}$ agents of group 2. However, the intermediary cannot credibly make losses at this stage, i.e., cannot credibly subsidize agents to move. The intermediary would have to pay a subsidy if its platform were less attractive than the old one, i.e., if it comprised less than half of the agents of the first group. Formally, we check that the highest fee compatible with all agents of group 2 moving is

$$
A_{2}=\pi_{2}\left(n_{1}\right)-\pi_{2}\left(N_{1}-n_{1}\right)
$$

which is positive as long as $n_{1} \geq N_{1} / 2$. In other words, the optimal number of agents the intermediary attracts is

$$
n_{2}^{*}\left(n_{1}\right)= \begin{cases}N_{2} & \text { if } n_{1} \geq N_{1} / 2 \\ 0 & \text { otherwise }\end{cases}
$$

Regarding stage 2, let us first show that we cannot have a Nash equilibrium with $0<n_{1}<N_{1}$ agents of group 1 switching. Such an equilibrium requires that the following two conditions be satisfied:

$$
\left\{\begin{array}{l}
\pi_{1}\left(n_{2}^{*}\left(n_{1}\right)\right)-A_{1} \geq \pi_{1}\left(N_{2}-n_{2}^{*}\left(n_{1}-1\right)\right), \\
\pi_{1}\left(N_{2}-n_{2}^{*}\left(n_{1}\right)\right)>\pi_{1}\left(n_{2}^{*}\left(n_{1}+1\right)\right)-A_{1} .
\end{array}\right.
$$

Note that the reasoning is more complicated than in stage 4 as by moving from one platform to the other, an agent of group 1 rationally anticipates that her move may modify the number of agents of group 2 that the intermediary will subsequently attract. In other words, there are values of $n_{1}$ for which $n_{2}^{*}\left(n_{1}\right) \neq n_{2}^{*}\left(n_{1}-1\right)$ or $n_{2}^{*}\left(n_{1}\right) \neq n_{2}^{*}\left(n_{1}+1\right)$, meaning that we are not in the conditions of Lemma 1 and that we have to check for all 


\begin{tabular}{|l|ccc|c|}
\hline & \multicolumn{3}{|c|}{$n_{2}^{*}(\cdot)$} & \multirow{2}{*}{} \\
\cline { 2 - 4 } & $n_{1}-1$ & $n_{1}$ & $n_{1}+1$ & $(1)$ \\
\hline $0<n_{1}<\frac{N_{1}}{2}-1$ & 0 & 0 & 0 & $\pi_{1}\left(N_{2}\right) \leq-A_{1}<\pi_{1}\left(N_{2}\right)$ \\
$n_{1}=\frac{N_{1}}{2}-1$ & 0 & 0 & $N_{2}$ & $\pi_{1}\left(N_{2}\right) \leq-A_{1}<0$ \\
$n_{1}=\frac{N_{1}}{2}$ & 0 & $N_{2}$ & $N_{2}$ & $\pi_{1}\left(N_{2}\right)<A_{1} \leq 0$ \\
$\frac{N_{1}}{2}<n_{1}<N_{1}$ & $N_{2}$ & $N_{2}$ & $N_{2}$ & $\pi_{1}\left(N_{2}\right)<A_{1} \leq \pi_{1}\left(N_{2}\right)$ \\
\hline
\end{tabular}

Table 1: Conditions for stage 2 equilibrium

possibilities. As demonstrated in Table 1, the conditions in (1) can never be met simultaneously, which proves our result.

There are thus two potential equilibria. All agents of group 1 make the same decisions: they either all stay with the existing platform, or they all switch to the new one:

$$
n_{1}^{*}= \begin{cases}N_{1} & \text { if } A_{1} \leq \pi_{1}\left(N_{2}\right), \\ 0 & \text { if } A_{1}>-\pi_{1}\left(N_{2}\right) .\end{cases}
$$

Note that we have simultaneous equilibria for all $-\pi_{1}\left(N_{2}\right)<A_{1} \leq \pi_{1}\left(N_{2}\right)$.

We can now consider stage 1. As we explained above, we require unique implementation on the part of the intermediary. As the situation with $n_{1}=$ 0 is clearly unprofitable, the intermediary has to set a fee such that $n_{1}=N_{1}$ is the unique equilibrium in stage 2 . That is, we must have $A_{1}=-\pi_{1}\left(N_{2}\right)$. This is the largest fee (i.e., the lowest subsidy) that makes sure that all agents of group 1 will switch and will then be followed by all agents of group 2. The question remains as to whether the intermediary can extract positive profits from this divide-and-conquer strategy. It is so if $\Pi_{I}^{(1)} \equiv$ $-N_{1} \pi_{1}\left(N_{2}\right)+N_{2} \pi_{2}\left(N_{1}\right)>0$. Alternatively, the intermediary could target group 2 first and obtain a profit of $\Pi_{I}^{(2)} \equiv-N_{2} \pi_{2}\left(N_{1}\right)+N_{1} \pi_{1}\left(N_{2}\right)$. It is clear that there is necessarily one of the two options that allows the intermediary to secure a positive profit.

In any case, the optimal conduct consists first in subsidizing the lowvalue group and then in taxing the high-value group. Ex post, the agents of the high-value group have their initial benefits completely taxed away. The proceeds of this "tax" finance the subsidy paid to the agents of the low-value group; this subsidy is equal to their initial benefits, so that they 


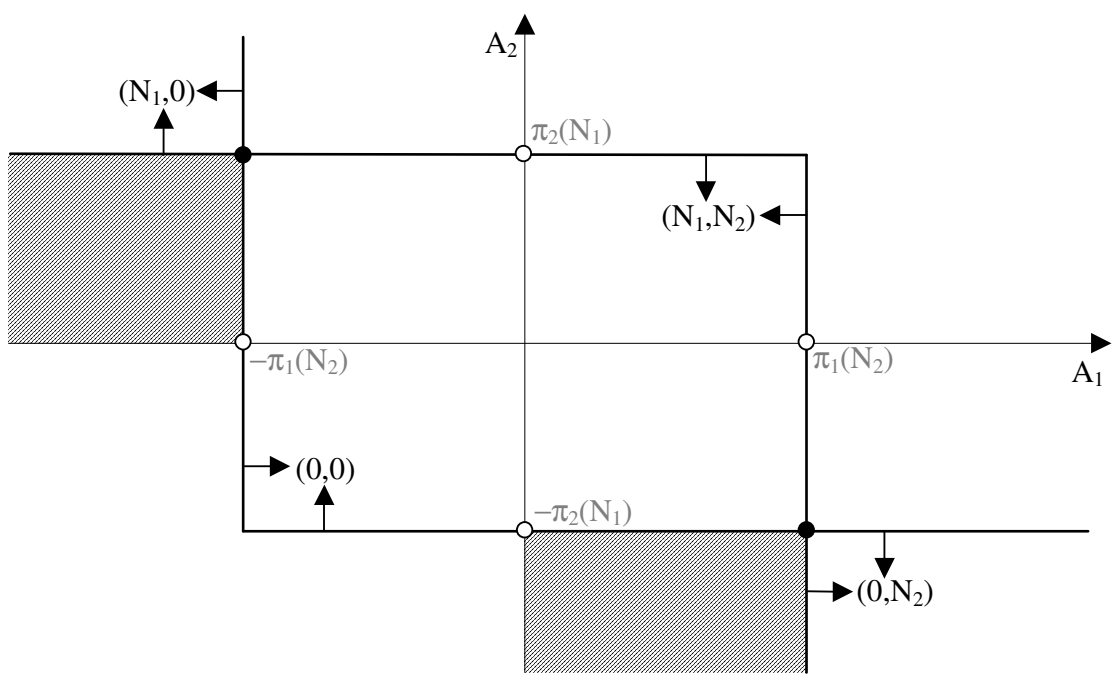

Figure 1: Simultaneous switching game with no rivalry

are twice as well off as before. Because there remains a positive balance, the intermediary finds it optimal to launch the new platform.

\section{$3.2 \quad$ Simultaneous switching}

Groups 1 and 2 are now supposed to move at the same time, after observing the two fees set by the intermediary. Regarding stage 2, we can apply Lemma 1 and conclude that all agents in one group will act the same. Therefore, the four possible equilibria are defined by the following conditions and are represented in Figure 1:

$$
\begin{array}{r}
(0,0) \text { if }\left\{\begin{array} { l } 
{ A _ { 1 } > - \pi _ { 1 } ( N _ { 2 } ) } \\
{ A _ { 2 } > - \pi _ { 2 } ( N _ { 1 } ) }
\end{array} \quad ( N _ { 1 } , 0 ) \text { if } \left\{\begin{array}{c}
A_{1} \leq-\pi_{1}\left(N_{2}\right) \\
A_{2}>\pi_{2}\left(N_{1}\right)
\end{array}\right.\right. \\
\left(0, N_{2}\right) \text { if }\left\{\begin{array} { c } 
{ A _ { 1 } > \pi _ { 1 } ( N _ { 2 } ) } \\
{ A _ { 2 } \leq - \pi _ { 2 } ( N _ { 1 } ) }
\end{array} \quad ( N _ { 1 } , N _ { 2 } ) \text { if } \left\{\begin{array}{c}
A_{1} \leq \pi_{1}\left(N_{2}\right) \\
A_{2} \leq \pi_{2}\left(N_{1}\right)
\end{array}\right.\right.
\end{array}
$$

Moving now to stage $\mathbf{1}$, we observe first that among the four possible equilibria, only one may be profitable for the intermediary, namely $\left(N_{1}, N_{2}\right) .{ }^{11}$ To implement it as a unique and profitable equilibrium, the

\footnotetext{
${ }^{11}$ In the $(0,0)$ case, no agent moves and thus no profit can me made; in the other two cases, no fee can be extracted from the group which does not move while subsidies have
} 
intermediary must choose $A_{1}$ and $A_{2}$ in the shaded areas of Figure 1. The intermediary's profits write as $N_{1} A_{1}+N_{2} A_{2}$. As they increase in $A_{1}$ and $A_{2}$, there are two potential optima: $\left[A_{1}, A_{2}\right] \in\left\{\left[-\pi_{1}\left(N_{2}\right), \pi_{2}\left(N_{1}\right)\right]\right.$, $\left.\left[\pi_{1}\left(N_{2}\right),-\pi_{2}\left(N_{1}\right)\right]\right\}$. It is clear that one of the two yields positive profits (and the other one yields losses). Therefore, the optimum is the one giving positive profits and corresponds to the same divide-and-conquer strategy adopted in the sequential switching game.

We summarize our results in the following proposition.

Proposition 2 In the absence of intra-group externalities, the intermediary always finds a profitable way to enter whether the groups of agents move sequentially or simultaneously. He attracts all agents of both groups. The optimal divide-and-conquer strategy consists in subsidizing the agents of the low-value group (with a subsidy $A_{i}=-\pi_{i}\left(N_{j}\right)$ ), and in taxing away the benefits of the agents of the high-value group (with a fee $A_{j}=\pi_{j}\left(N_{i}\right)$ ).

\section{Sequential switching with rivalry}

We now index by $r$ the rival agents and by $i$ the independent (i.e., non rival) agents. We denote their respective benefit functions by $\pi_{r}\left(n_{i}, n_{r}\right)$ and $\pi_{i}\left(n_{r}\right)$. From the intermediary's point of view, rivalry is a mixed blessing. On the one hand, the intermediary finds it easier to attract a small set of rival agents as they are willing to pay more in order to stay away from the crowd. On the other hand, the very same reason makes it harder to attract a large set of rival agents and thereby to make the platform attractive for independent agents. Therefore, it is not clear a priori whether rivalry on one side facilitates the launch of the new platform.

As we now show, the presence of rivalry complicates the analysis in a number of ways: first, the group of rival agents might partition at equilibrium; second, the order of moves now crucially matters in the sequential switching game; third, the sequential and simultaneous switching games may yield different outcomes.

to be paid to the other group. 


\subsection{Rival agents moving first}

We consider first the sequential game in which the intermediary sets first the fee for the rival agents, and then the fee for the independent agents. We derive the following proposition.

Proposition 3 In the sequential switching game with rival agents moving first, the candidate optimum for the intermediary is to attract all agents of both groups. To do so, he subsidizes the rival agents by setting $A_{r}=$ $-\pi_{r}\left(N_{i}, \frac{N_{r}}{2}+2\right)$ and he extracts all the benefits of the independent agents by setting $A_{i}=\pi_{i}\left(N_{r}\right)$. This scheme is indeed optimal if it generates positive profits, i.e., if

$$
N_{i} \pi_{i}\left(N_{r}\right)>\beta_{r f} \equiv N_{r} \pi_{r}\left(N_{i}, \frac{N_{r}}{2}+2\right)
$$

The proof of this proposition is relegated to Appendix 8.1. Here, we give the intuition.

From Lemma 1, independent agents behave the same way: they all move or they all stay. Clearly the only way for the intermediary to make profits is to have them all moving, which requires attracting at least half of the rival agents in the second stage (if not he would have to subsidize independent agents, which is not profit maximizing).

Now, unique implementation of an equilibrium with at least half of the rival agents moving compels the intermediary to pay them a subsidy. Indeed, to exclude the non profitable equilibrium in which none of the rival agents moves, the intermediary needs to set $A_{r} \leq-\pi_{r}\left(N_{i}, N_{r}\right)$, i.e., to compensate rival agents for the initial benefit they make on the old platform. Yet, if $A_{r}=$ $-\pi_{r}\left(N_{i}, N_{r}\right)-\varepsilon$, there exists another non profitable equilibrium in which only one rival agent moves. By moving, this agent earns the subsidy $\left(-A_{r}\right)$ which is larger than $\pi_{r}\left(N_{i}, N_{r}\right)$; on the other hand, no other agent has an incentive to move along as they earn $\pi_{r}\left(N_{i}, N_{r}-1\right)$ which is larger than the subsidy. To eliminate this equilibrium, the intermediary has to pay a larger subsidy, i.e., $A_{r} \leq-\pi_{r}\left(N_{i}, N_{r}-1\right)$. Then, repeating the argument, there exists yet another non profitable equilibrium with two rival agents moving, which has to be eliminated. And so on. The sequence of non profitable situations ends up with $N_{r} / 2-1$ rival agents moving; but we show in the 
proof of the proposition that this situation cannot be an equilibrium. Hence, we apply the recursive argument up to the equilibrium where $N_{r} / 2-2$ rival agents move, which is eliminated by setting $A_{r}=-\pi_{r}\left(N_{i}, N_{r}-\left(\frac{N_{r}}{2}-2\right)\right)$.

This subsidy ensures that none of the non profitable situations is an equilibrium. So the remaining potential equilibria are such that at least half of the rival agents move and are thus followed by all independent agents. As by staying on the old platform, the rival agents would make zero benefit, they all prefer to move and earn a positive benefit augmented by the subsidy. Therefore the unique equilibrium is such that all rival agents move.

Finally, for this equilibrium to be profitable for the intermediary, condition (2) must be satisfied, that is, total fees must be larger than total subsidies: $N_{i} \pi_{i}\left(N_{r}\right)>N_{r} \pi_{r}\left(N_{i}, \frac{N_{r}}{2}+2\right)$. Because rival agents are paid a subsidy that is larger than their initial benefit, it is necessary but not sufficient that the rival (subsidized) group be the low-value group. If $N_{r} \pi_{r}\left(N_{i}, \frac{N_{r}}{2}+2\right)>N_{i} \pi_{i}\left(N_{r}\right)>N_{r} \pi_{r}\left(N_{i}, N_{r}\right)$, the rival group is the lowvalue group but entry is not profitable. We return to this finding when analyzing the intermediary's entry decision.

\subsection{Rival agents moving second}

We now reverse the order of moves: independent agents move before rival agents. We start by analyzing the last two stages. Next, we introduce one additional assumption about the benefit functions in order to solve the first two stages. We collect our main results in Proposition 4 below.

In stage 4 , the rivalry between agents implies that any partition of that group can emerge at the equilibrium. An equilibrium with $0<n_{r}<N_{r}$ agents switching requires

$$
\left\{\begin{array}{l}
\pi_{r}\left(n_{i}, n_{r}\right)-A_{r} \geq \pi_{r}\left(N_{i}-n_{i}, N_{r}-n_{r}+1\right), \\
\pi_{r}\left(N_{i}-n_{i}, N_{r}-n_{r}\right)>\pi_{r}\left(n_{i}, n_{r}+1\right)-A_{r} .
\end{array}\right.
$$

Define

$$
a_{r}\left(n_{i}, n_{r}\right) \equiv \pi_{r}\left(n_{i}, n_{r}\right)-\pi_{r}\left(N_{i}-n_{i}, N_{r}-n_{r}+1\right) .
$$

The two conditions for an equilibrium with $0<n_{r}<N_{r}$ can then be 
reexpressed as

$$
a_{r}\left(n_{i}, n_{r}+1\right)<A_{r} \leq a_{r}\left(n_{i}, n_{r}\right) .
$$

Similarly, we have an equilibrium with $n_{r}=0$ if $A_{r}>a_{r}\left(n_{i}, 1\right)$ and an equilibrium with $n_{r}=N_{r}$ if $A_{r} \leq a_{r}\left(n_{i}, N_{r}\right)$.

The function $a_{r}\left(n_{i}, n_{r}\right)$ measures the highest fee a rival agent is willing to pay for joining the new platform on which $n_{i}$ independent agents and $n_{r}$ rival agents are active. As $a_{r}\left(n_{i}, n_{r}\right)$ decreases with $n_{r}$, it can be seen as a demand function for the new platform; as $a_{r}\left(n_{i}, n_{r}\right)$ increases with $n_{i}$, this demand function moves upward when more independent agents are present on the new platform.

As $a_{r}\left(n_{i}, n_{r}\right)$ decreases with $n_{r}$, the $\left(n_{r}+1\right)$ above conditions define a sequence of adjacent intervals, meaning that any value of $A_{r}$ corresponds to a unique equilibrium. Hence, in stage $\mathbf{3}$, the intermediary's problem is equivalent to choosing the value of $n_{r}$ that maximizes its revenue: $n_{r} a_{r}\left(n_{i}, n_{r}\right)$.

To proceed with the solution of the game, we impose some additional structure on the generic benefit functions. We make the following assumption:

Assumption 1. The global maximum of $n_{r} a_{r}\left(n_{i}, n_{r}\right), n_{r}^{*}\left(n_{i}\right)$, is weakly increasing in $n_{i}$.

This assumption seems natural: it says that the value of $n_{r}$ that the intermediary determines in stage 3 does not decrease if more independent agents have been attracted beforehand. ${ }^{12}$ Naturally, $n_{r}^{*}(0)=0$. Indeed, if no independent agent switched beforehand, the intermediary would have to pay subsidies to rival agents, which he cannot credibly do at this stage (as he always has the possibility to shut his activity down).

The analysis of stages 1 and 2 is more technical and is relegated to Appendix 8.2. Here we just sketch the argument. At stage 2, when an independent agent switches to the new platform, he generates a positive network externalities for the other independent agents as his switch incites the intermediary to attract more rival agents (by Assumption 1). Hence, if one independent agent moves then all the others follow suit. At stage 1, by setting a fee that induces one independent agent to move, the intermediary

\footnotetext{
${ }^{12}$ This assumption is fulfilled in the two specific examples we consider below.
} 
uniquely implements the equilibrium in which all independent agents move. This fee is computed as $A_{i}=\pi_{i}\left(n_{r}^{*}(1)\right)-\pi_{i}\left(N_{r}\right) \leq 0$, i.e., the difference between the benefit the agent obtains if moving alone to the new platform and his initial benefit. Note that if $n_{r}^{*}(1)>0$ (i.e., if the intermediary finds it optimal to attract rival agents even if there is only one independent agent), then the subsidy is lower than the initial benefit of an independent agent.

Moving down the equilibrium path, we observe that the intermediary is able to extract the entire benefits of the rival agents he attracts. Indeed, all independent agents switch and according to (3), we have that $a_{r}\left(N_{i}, n_{r}\right)=$ $\pi_{r}\left(N_{i}, n_{r}\right)$. By the same token, the equilibrium number of rival agents on the new platform is given by $n_{r}^{*}\left(N_{i}\right)=\arg \max _{n_{r}} n_{r} \pi_{r}\left(N_{i}, n_{r}\right)$.

We therefore state our main results.

Proposition 4 In the sequential switching game with rival agents moving second, the candidate optimum for the intermediary is to attract all $N_{i}$ independent agents and a number $n_{r}^{*}\left(N_{i}\right)$ of rival agents, where $n_{r}^{*}\left(n_{i}\right)=$ $\arg \max _{n_{r}} n_{r} a_{r}\left(n_{i}, n_{r}\right)$. To do so, he subsidizes the independent agents by setting $A_{i}=\pi_{i}\left(n_{r}^{*}(1)\right)-\pi_{i}\left(N_{r}\right) \leq 0$ and he extracts all the benefits of the rival agents by setting $A_{r}=\pi_{r}\left(N_{i}, n_{r}^{*}\left(N_{i}\right)\right)$. This scheme is indeed optimal if it generates positive profits, i.e., if

$$
N_{i} \pi_{i}\left(N_{r}\right)<\beta_{i f} \equiv N_{i} \pi_{i}\left(n_{r}^{*}(1)\right)+n_{r}^{*}\left(N_{i}\right) \pi_{r}\left(N_{i}, n_{r}^{*}\left(N_{i}\right)\right) .
$$

\subsection{Entry decision}

In the absence of rivalry, the intermediary always finds a profitable way to launch the new platform; he does so by subsidizing the low-value group and taxing the high-value group. The presence of rivalry introduces two fundamental changes. First and foremost, the intermediary might not find a profitable way to launch the new platform. Second, when the intermediary finds a profitable way to enter, he might have to subsidize the independent group although it is the high-value group.

To understand the first statement, start from the case with no rivalry: $n_{r}^{*}(1)=0, n_{r}^{*}\left(N_{i}\right)=N_{r}$ and $\pi_{r}($.$) does not depend on n_{r}$. Then, we see 
that $\beta_{r f}=\beta_{i f}$, which implies that one of the two strategies (attracting rival or independent agents first) is profitable. Now, introduce rivalry. For weak rivalry, we still have (by continuity) that $n_{r}^{*}(1)=0$ and $n_{r}^{*}\left(N_{i}\right)=N_{r}$. However, rival agents' benefits now decrease with $n_{r}$, which introduces a wedge between the total tax that can be levied on rival agents when they move second, i.e., $N_{r} \pi_{r}\left(N_{i}, \frac{N_{r}}{2}+2\right)$, and the total subsidy that must be paid to them if they move first, i.e., $N_{r} \pi_{r}\left(N_{i}, N_{r}\right)$. As the subsidy to be paid or the tax to be levied on independent agents is the same $\left(N_{i} \pi_{i}\left(N_{r}\right)\right)$, we can have situations where no strategy yields a profit. That is, using conditions (2) and (4) in Propositions 3 and 4, we can have situations where $\beta_{i f}<N_{i} \pi_{i}\left(N_{r}\right)<\beta_{r f}$ and the intermediary makes losses whatever the group he attracts first. These situations become less likely as rivalry gets stronger. Indeed, $n_{r}^{*}(1)$ eventually becomes positive (i.e., the intermediary attracts rival agents even in the presence of a single independent agent) and this makes it possible to have $\beta_{i f}>\beta_{r f}$. This is so because the subsidy necessary to attract independent agents is smaller than their initial benefit when $n_{r}^{*}(1)>0$; therefore, the profitability of attracting independent agents first increases. Note that the notions of "weak" and "strong" rivalry can only be made precise when we consider specific benefit functions, as we do in Section 6.

For the second statement, we must first redefine the notion of highand low-value group. What matters is the highest total benefits that each group can reach; that is, $N_{i} \pi_{i}\left(N_{r}\right)$ for the independent group, and $\gamma_{s i} \equiv$ $n_{r}^{*}\left(N_{i}\right) \pi_{r}\left(N_{i}, n_{r}^{*}\left(N_{i}\right)\right)$ for the rival group. ${ }^{13}$ Notice that $\beta_{i f}=N_{i} \pi_{i}\left(n_{r}^{*}(1)\right)+$ $n_{r}^{*}\left(N_{i}\right) \pi_{r}\left(N_{i}, n_{r}^{*}\left(N_{i}\right)\right)>\gamma_{s i}$ as long as $n_{r}^{*}(1)>0$. Therefore, it might be the case that $\gamma_{s i}<N_{i} \pi_{i}\left(N_{r}\right)<\beta_{i f}$; which implies that the intermediary chooses to subsidize the independent group although it is the high-value group. Since the subsidy necessary to attract independent agents is smaller than their initial benefit, the total subsidy might still be covered by the total tax levied on the rival agents. Figure ??, which is drawn for the case where $\beta_{r f}>\beta_{i f}$, illustrates these two important results.

\footnotetext{
${ }^{13}$ To find the highest total benefits for the rival group, we solve $\max _{n_{i}, n_{r}} n_{r} \pi_{r}\left(n_{i}, n_{r}\right)$. As $\pi_{r}$ increases in $n_{i}$, it is best to set $n_{i}=N_{i}$ and by definition, $n_{r}^{*}\left(N_{i}\right)$ is the maximum of $n_{r} \pi_{r}\left(N_{i}, n_{r}\right)$.
} 


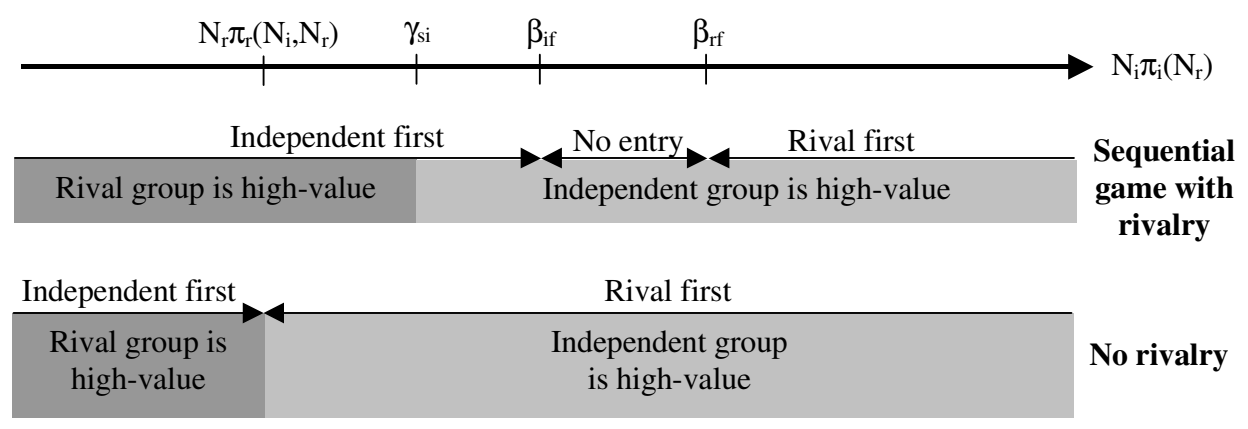

Figure 2: Entry decision with sequential switching

\section{Simultaneous switching with rivalry}

When agents move simultaneously, the game only has two stages: the intermediary fixes first $A_{i}$ and $A_{r}$ and then the agents make their switching decision. Regarding stage 2, we apply Lemma 1 to conclude that all independent agents make the same decision, meaning that the only two possible equilibrium values for $n_{i}$ are 0 if $A_{i}>\pi_{i}\left(n_{r}\right)-\pi_{i}\left(N_{r}-n_{r}\right)$, and $N_{i}$ if $A_{i} \leq \pi_{i}\left(n_{r}\right)-\pi_{i}\left(N_{r}-n_{r}\right)$. As for the rival group, all partitions can emerge at equilibrium. Rival agents split between the two platforms if

$$
a_{r}\left(n_{i}, n_{r}+1\right)<A_{r} \leq a_{r}\left(n_{i}, n_{r}\right) .
$$

They all stay on the existing platform if $A_{r}>a_{r}\left(n_{i}, 1\right)$, or they all switch to the new platform if $A_{r} \leq a_{r}\left(n_{i}, N_{r}\right)$.

We thus have six possible types of equilibria, under the following sets of conditions, which are represented in Figure 3.

$$
\begin{aligned}
& (0,0) \text { if }\left\{\begin{array} { l } 
{ A _ { r } > - \pi _ { r } ( N _ { i } , N _ { r } ) } \\
{ A _ { i } > - \pi _ { i } ( N _ { r } ) , }
\end{array} \quad ( N _ { i } , N _ { r } ) \quad \text { if } \left\{\begin{array}{l}
A_{r} \leq \pi_{r}\left(N_{i}, N_{r}\right) \\
A_{i} \leq \pi_{i}\left(N_{r}\right),
\end{array}\right.\right. \\
& \left(N_{i}, 0\right) \text { if }\left\{\begin{array} { l } 
{ A _ { r } > \pi _ { r } ( N _ { i } , 1 ) } \\
{ A _ { i } \leq - \pi _ { i } ( N _ { r } ) , }
\end{array} \quad \text { if } \left\{\begin{array}{l}
A_{r} \leq-\pi_{r}\left(N_{i}, 1\right) \\
A_{i}>\pi_{i}\left(N_{r}\right),
\end{array}\right.\right. \\
& \left(0, n_{r}\right) \text { if }\left\{\begin{array}{l}
-\pi_{r}\left(N_{i}, N_{r}-n_{r}\right)<A_{r} \leq-\pi_{r}\left(N_{i}, N_{r}-n_{r}+1\right), \\
A_{i}>\pi_{i}\left(n_{r}\right)-\pi_{i}\left(N_{r}-n_{r}\right),
\end{array}\right. \\
& \left(N_{i}, n_{r}\right) \text { if }\left\{\begin{array}{l}
\pi_{r}\left(N_{i}, n_{r}+1\right)<A_{r} \leq \pi_{r}\left(N_{i}, n_{r}\right), \\
A_{i} \leq \pi_{i}\left(n_{r}\right)-\pi_{i}\left(N_{r}-n_{r}\right) .
\end{array}\right.
\end{aligned}
$$




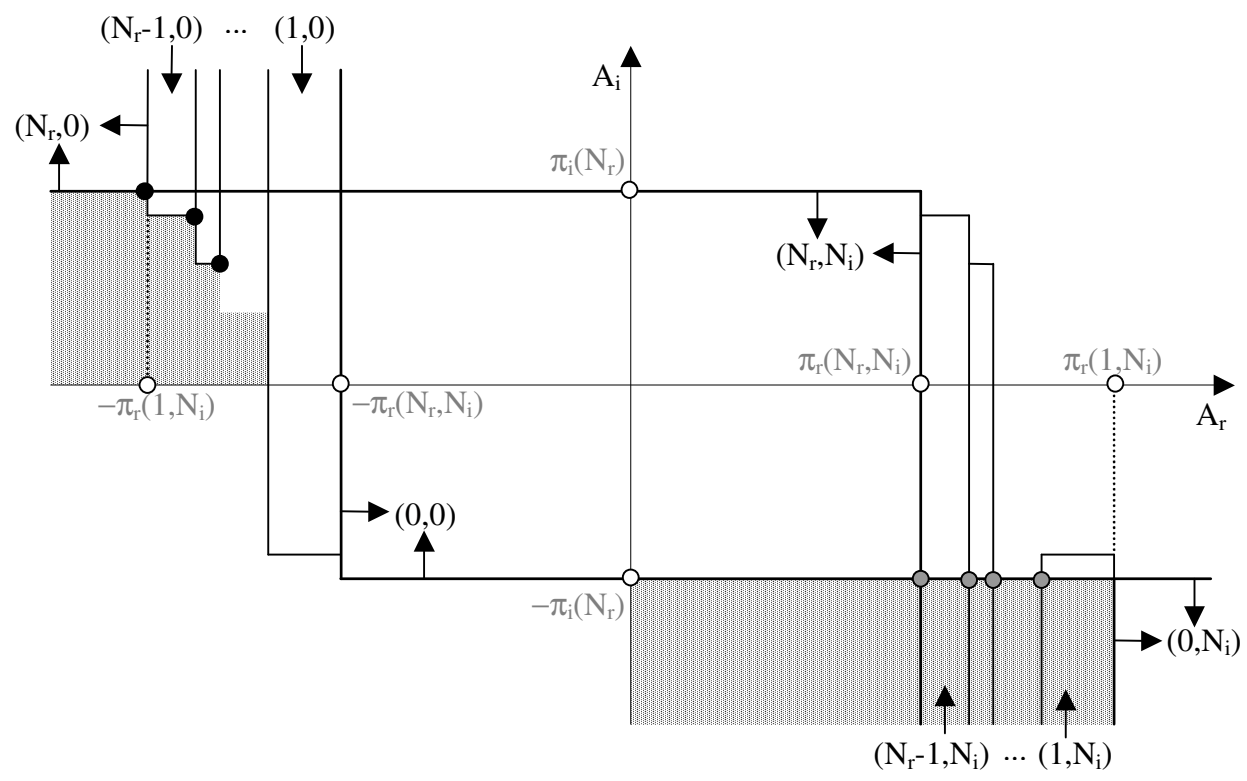

Figure 3: Simultaneous switching game with rivalry

In stage 1, the intermediary can only make profit if some of the agents he attracts pay a positive fee (which excludes the South-West quadrant of Figure 3$)$. This means that only equilibria of the type $\left(N_{i}, N_{r}\right)$ or $\left(N_{i}, n_{r}\right)$ can yield a positive profit to the intermediary. Turning now to the uniqueness requirement, we observe in Figure 3 that it is not possible that both groups of agents pay a positive fee (since no participation is then necessarily an equilibrium). We thus focus on the two off-diagonal quadrants, in which we exclude the non profitable equilibria involving no participation from one or the other group, i.e., $(0,0),\left(N_{i}, 0\right),\left(0, N_{r}\right)$ and $\left(0, n_{r}\right)$. What is left corresponds to the two shaded areas of Figure 3: the subsidized rival area (top-left) and the subsidized independent area (bottom-right). We now characterize these two areas analytically.

In the subsidized rival area, the equilibrium is $\left(N_{i}, N_{r}\right)$ : the intermediary attracts all agents of both groups. He maximizes his profits by choosing, for a given $A_{r}$, the highest possible $A_{i}$ within the limits of the area. The subsidy 
given to the rival group is computed so as to eliminate unprofitable equilibria where $n_{r}$ rival agents switch and are not accompanied by any independent agent. That is, the optimum is to be found among the black dots in Figure 3, which are defined by $A_{r}=-\pi_{r}\left(N_{i}, x\right)$ and $A_{i}=\pi_{i}\left(N_{r}-x+1\right)-\pi_{i}(x-1)$. Hence, in this area, the intermediary finds the optimal combination of fees by choosing

$$
x^{*} \in \arg \max _{x} \Pi_{I}^{s r}(x)=-N_{r} \pi_{r}\left(N_{i}, x\right)+N_{i}\left(\pi_{i}\left(N_{r}-x+1\right)-\pi_{i}(x-1)\right) .
$$

This scheme is profitable for the intermediary as long as $\Pi_{I}^{s r}\left(x^{*}\right) \geq 0$ or equivalently

$N_{i} \pi_{i}\left(N_{r}\right)>\gamma_{s r} \equiv N_{r} \pi_{r}\left(N_{i}, x^{*}\right)+N_{i}\left(\pi_{i}\left(N_{r}\right)-\pi_{i}\left(N_{r}-x^{*}+1\right)+\pi_{i}\left(x^{*}-1\right)\right)$.

Note that $1 \leq x^{*} \leq N_{r} / 2$, as $x^{*}>N_{r} / 2$ would mean that independent agents are subsidized.

In the subsidized independent area, equilibria are of the type $\left(N_{i}, n_{r}\right)$ with $1 \leq n_{r} \leq N_{r}$. The independent group is granted a subsidy equal to $A_{i}=-\pi_{i}\left(N_{r}\right)$, which corresponds to the lowest subsidy excluding the noparticipation equilibrium. To determine the optimal number of rival agents to attract, the intermediary selects the highest possible $A_{r}$ for a given $A_{i}$ within the limits of the area. That is, he chooses between the gray dots in Figure 3 and finds the optimum by solving:

$$
\hat{n}_{r} \in \arg \max _{n_{r}} \Pi_{I}^{s i}=n_{r} \pi_{r}\left(N_{i}, n_{r}\right)-N_{i} \pi_{i}\left(N_{r}\right) .
$$

As $N_{i} \pi_{i}\left(N_{r}\right)$ does not depend on $n_{r}, \hat{n}_{r}=n_{r}^{*}\left(N_{i}\right)$, as defined in the previous section. This scheme is profitable for the intermediary as long as $\Pi_{I}^{s i}\left(n_{r}^{*}\left(N_{i}\right)\right) \geq 0$ or equivalently

$$
N_{i} \pi_{i}\left(N_{r}\right)<\gamma_{s i}=n_{r}^{*}\left(N_{i}\right) \pi_{r}\left(N_{i}, n_{r}^{*}\left(N_{i}\right)\right)
$$

We summarize our results in the following proposition.

Proposition 5 In the simultaneous switching game with rivalry, the intermediary has two options. The first option is to subsidize rival agents and to 


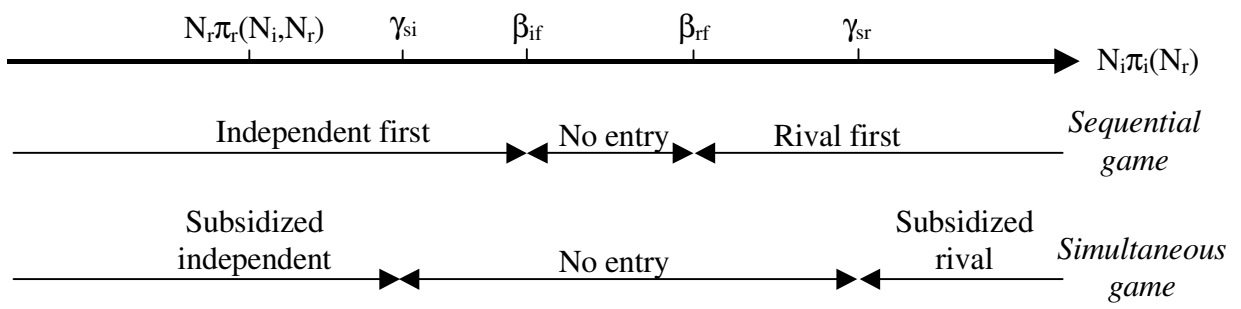

Figure 4: Entry decision with simultaneous switching

tax independent agents so as to attract all agents of both types. This option is profitable as long as $N_{i} \pi_{i}\left(N_{r}\right)>\gamma_{s r}$. The second option is to subsidize independent agents and to tax rival agents so as to attract all independent agents and a number $1 \leq n_{r}^{*}\left(N_{i}\right) \leq N_{r}$ of rival agents. This option is profitable as long as $N_{i} \pi_{i}\left(N_{r}\right)<\gamma_{s i}$.

Consider now the intermediary's entry decision. It is clear from Proposition 5 that there is no profitable way to enter if $\gamma_{s i}<N_{i} \pi_{i}\left(N_{r}\right)<\gamma_{s r}$, as depicted on Figure 4. The problem is more acute than in the sequential game. It is clear that $\beta_{i f} \geq \gamma_{s i}$ (with $\beta_{i f}=\gamma_{s i}$ if $n_{r}^{*}(1)=0$ ). It is also true that $\gamma_{s r}>\beta_{r f}$ (the first term of $\gamma_{s r}$ is larger than $\beta_{r f}$ as $x^{*} \leq N_{r} / 2$ and $\pi_{r}$ decreases in its second argument; the second term of $\gamma_{s r}$ is positive). It follows that $\gamma_{s i}-\gamma_{s r}<\beta_{i f}-\beta_{r f}$. So, if $\beta_{i f}-\beta_{r f}<0$, then $\gamma_{s i}-\gamma_{s r}<0$ : if it is not profitable to enter in the sequential game, it is also not profitable to enter in the simultaneous game. Thus, sequentiality makes entry easier for the intermediary. Indeed, sequentiality reduces the number of simultaneous equilibria and, thereby, alleviates the constraints imposed by the requirement of unique implementation (which translates into lower subsidies to be paid).

\section{Applications}

\subsection{Linear specification}

We consider first a simple example with linear benefit functions. This allows to separate neatly the rivalry effect from the indirect network effect. We 


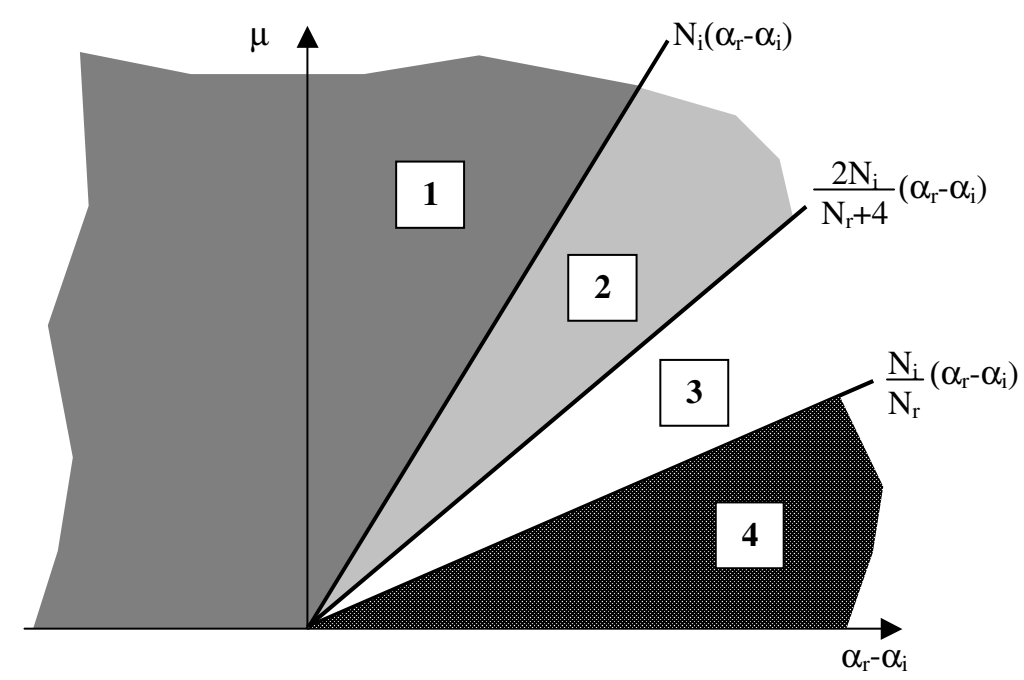

1. Subsidize rival agents. 2. Subsidize rival agents (sequential) / No profit (simultaneous). 3. No profit. 4. Subsidize independent agents

(Independent agents form the high-value group in 1, 2 and 3; rival agents do in 4.)

Figure 5: Equilibria under linear specification

posit

$$
\begin{aligned}
\pi_{r}\left(n_{i}, n_{r}\right) & = \begin{cases}\alpha_{r} n_{i}-\mu n_{r} & \text { if } n_{i}>0 \\
0 & \text { if } n_{i}=0\end{cases} \\
\pi_{i}\left(n_{r}\right) & =\alpha_{i} n_{r}
\end{aligned}
$$

where $\alpha_{r}$ and $\alpha_{i}$ measure the indirect network effect respectively for the rival and the independent agents, and $\mu$ measures the competition effect among rival agents. We assume that $\alpha_{r}, \alpha_{i}$, and $\mu$ are positive and that $\mu N_{r}<\alpha_{r}$; the latter condition limits the rivalry effect so as to guarantee that rival agents always earn positive benefits. ${ }^{14}$

In Appendix 8.4, we compute the expressions $\beta_{i f}, \beta_{r f}, \gamma_{s i}, \gamma_{s r}$ and we express the results of Propositions 3, 4 and 5 by comparing the competition effect, $\mu$, with the difference in indirect network effects between the two groups, $\left(\alpha_{r}-\alpha_{i}\right)$. The results are depicted in Figure 5.

\footnotetext{
${ }^{14}$ For the sake of the presentation, we focus here on the case where $\mu N_{r}<2 N_{i} \alpha_{i}$. We show in Appendix 8.4 that similar results obtain if this assumption is relaxed.
} 
Start with Region 4. In this region, $\alpha_{r}>\alpha_{i}$ and $\mu$ is small, meaning that rival agents form the high value group. Formally, $N_{r}\left(\alpha_{r} N_{i}-\mu N_{r}\right)>$ $N_{i} \alpha_{i} N_{r} \Leftrightarrow \mu<\left(N_{i} / N_{r}\right)\left(\alpha_{r}-\alpha_{i}\right)$. The optimal conduct for the intermediary is therefore to tax the benefits of rival agents and to subsidize independent agents. Moving to Region 3, we have now that independent agents form the high-value group: although indirect network effects are stronger for rival agents $\left(\alpha_{r}>\alpha_{i}\right)$, the increase in rivalry reduces their benefits. The optimal conduct would be to tax independent agents. However, whatever the timing of moves, this strategy is not profitable. The reason is the following. The subsidy to be paid to the rival agents is larger than their initial benefits because their fall-back position increases as more rival agents move to the new platform. This explains why the total fees levied on the independent agents, although higher than rival agents' total benefits, fall short to cover the total subsidies. The latter result carries over to Region 2 as far as the simultaneous game is concerned. However, when agents move sequentially, the intermediary has to pay a lower subsidy to the rival agents and is now able to make a profit. Finally, in Region 1, the benefits of the rival agents are relatively small with respect to the benefits of the independent agents (because $\mu$ is large and/or $\alpha_{r}<\alpha_{i}$ ). Hence, it is not surprising that profits can be made by subsidizing rival agents and taxing independent agents, whatever the timing of moves.

\subsection{B2B commerce}

Our second application is a model of successive vertical oligopoly, which represents interaction between buyers and sellers of an intermediate input on a B2B platform. Consider a platform with $n_{i}$ buyers and $n_{r}$ sellers. Each buyer $\left(k=1, \ldots, n_{i}\right)$ produces a final product; the $n_{i}$ products are assumed to be perfectly differentiated, so that buyers are indeed independent agents. The inverse demand for each product is identical and is given by $p_{k}=1-q_{k}$. Suppose that the unit cost for a buyer is entirely given by the price $w$ paid for the intermediate product. The first-order condition for profit maximization yields $w=1-2 q_{k}=1-2\left(Q / n_{i}\right)$, where $Q$ is the total quantity of final products (and where $q_{k}=Q / n_{i}$ because of the symmetry of the model). 
Assuming that each buyer uses the same one-for-one transformation technology, we have that the total quantity of final products $(Q)$ is equal to the total quantity of the intermediate product $(X)$. The previous expression gives thus the inverse demand function for the sellers. So, seller $j$ (with $j=1, \ldots, n_{r}$ ), whose marginal cost of production is assumed to be equal to zero, has the following first-order condition for profit maximization: $1-\left(4 / n_{i}\right) x_{j}-\left(2 / n_{i}\right) X_{-j}=0$. At the symmetric Cournot equilibrium, each seller produces a quantity $x=n_{i} /\left(2\left(n_{r}+1\right)\right)$. Equilibrium profits are then equal to:

$$
\begin{aligned}
\text { for sellers, } \pi_{r}\left(n_{i}, n_{r}\right) & =\frac{n_{i}}{2\left(n_{r}+1\right)^{2}}, \\
\text { for buyers, } \pi_{i}\left(n_{r}\right) & =\frac{n_{r}^{2}}{4\left(n_{r}+1\right)^{2}} .
\end{aligned}
$$

These profit functions have the desired properties. First, they both exhibit indirect network effects: $\pi_{r}\left(n_{i}, n_{r}\right)$ increases with $n_{i}$, and $\pi_{i}\left(n_{r}\right)$ increases with $n_{r}$. Second, there is one rival group (the sellers) and one independent group (the buyers): $\pi_{r}\left(n_{i}, n_{r}\right)$ decreases with $n_{r}$, while $\pi_{i}\left(n_{r}\right)$ does not depend on $n_{i}$. However, in contrast with the previous linear example, the competition effect and the indirect effect cannot be separated in the benefit function of the rival agents. Considering briefly $n_{r}$ and $n_{i}$ as continuous variables for the sake of the argument, we have indeed that

$$
\frac{d^{2} \pi_{r}\left(n_{i}, n_{r}\right)}{d n_{i} d n_{r}}=\frac{-1}{\left(n_{r}+1\right)^{3}}<0,
$$

meaning that the indirect network effect decreases as more sellers are present on the same platform.

Although these profit functions are more intricate than in the linear example, the successive Cournot setting yields some clear-cut results about the intermediary's conduct. In particular, when the intermediary attracts independent buyers first, he always chooses to grant a monopoly to a single rival seller afterwards. Indeed, the intermediary chooses $n_{r}^{*}\left(n_{i}\right)$ as the maximum of

$$
n_{r} a_{r}\left(n_{i}, n_{r}\right)=n_{r} \pi_{r}\left(n_{i}, n_{r}\right)-n_{r} \pi_{r}\left(N_{i}-n_{i}, N_{r}-n_{r}+1\right) .
$$


First, we know from Amir (2003) that in a Cournot market for a homogeneous product with linear costs, industry profits are maximized under monopoly: we check indeed that $n_{r} \pi_{r}\left(n_{i}, n_{r}\right)$ decreases with $n_{r}$. Second, as more sellers move to the new platform, the fall back position of each seller (i.e., the profit a seller would achieve by unilaterally switching back to the old platform) improves; this means that the total compensation the intermediary has to pay, $n_{r} \pi_{r}\left(N_{i}-n_{i}, N_{r}-n_{r}+1\right)$, increases with $n_{r}$. As these two results are independent of the distribution of buyers between the two platforms, it follows that for all $n_{i} \geq 1, n_{r} a_{r}\left(n_{i}, n_{r}\right)$ decreases with $n_{r}$, meaning that the candidate optimum is $n_{r}^{*}\left(n_{i}\right)=1 .^{15}$ We learn from this result that the rivalry effect is strong in this model.

Another useful result is that the intermediary cannot profitably enter if he subsidizes the rival sellers in the simultaneous game. We show indeed in Appendix 8.4, that $\Pi_{I}^{s r}(x)<0 \forall 1 \leq x \leq N_{r}$. The threshold $\gamma_{s r}$ becomes thus irrelevant. We also establish that $N_{i} \pi_{i}\left(N_{r}\right)>\gamma_{s i}$, which means that the intermediary cannot enter profitably if he subsidizes the independent buyers instead (as shown in Proposition 5). Hence, in the B2B example, the new platform is not launched if agents move simultaneously.

As far as sequential switching is concerned, we show in the appendix that

$$
N_{r} \pi_{r}\left(N_{i}, N_{r}\right)<\beta_{r f}<\beta_{i f}<N_{i} \pi_{i}\left(N_{r}\right)
$$

Therefore (as shown in Propositions 3 and 4), the only way for the intermediary to enter profitably is to subsidize the rival sellers.

In sum, the B2B commerce example leads to sharp predictions. Because rivalry is fierce among sellers, sellers form the low-value group and so, the intermediary prefers to subsidize that group. This strategy turns out to be profitable when agents move sequentially, but not when they move simultaneously. Hence, the intermediary is better off when he can make the two groups of agents move sequentially rather than simultaneously.

\footnotetext{
${ }^{15}$ We show in Appendix 8.4 that $n_{r}^{*}(1)=1$ as long as $4 N_{i} \leq N_{r}^{2}+2 N_{r}+5$, which we assume here. This condition guarantees that $a_{r}(1,1) \geq 0$ (otherwise, $n_{r}^{*}(1)=0$ as there is no way for the intermediary to make profits). As for $n_{r}^{*}\left(N_{i}\right)$, it is always equal to 1 .
} 


\section{Conclusion}

We have considered the following setting: two types of agents interact on a pre-existing free platform; agents value positively the presence of agents of the other type but may value negatively the presence of agents of their own type. The issue was to investigate whether a new platform can find fees and subsidies so as to divert agents from the existing platform and make a profit. As we have shown, the answer hinges on the relative strength of intra-group negative externalities (i.e., rivalry) with respect to inter-group externalities (i.e., indirect network externalities). We can summarize our results as follows. In the absence of rivalry, the intermediary always finds a profitable way to launch the new platform; he does so by subsidizing the low-value group and taxing the high-value group. The presence of rivalry introduces one fundamental change: the intermediary might not find a profitable way to launch the new platform. This occurs when rivalry is neither too weak nor too strong. Otherwise, there exist divide-and-conquer strategies allowing the intermediary to make a profit. The effects of rivalry are thus non-monotonic.

The impossibility to launch a new platform is all the more striking that the existing platform is non strategic. A natural extension of our analysis would be to allow both platforms to act strategically, as in Caillaud and Jullien (2003); the issue would be to assess the effects of rivalry on the competition between for-profit platforms. One can conjecture that the presence of rivalry might break the positive feed-back forces of indirect network externalities and allow for the coexistence of a small and a large platform; the small platform would exploit rival agents' willingness to be isolated from their peers, whereas the large platform would take advantage of the usual inter-group externalities.

Another obvious extension would be to allow agents to multi-home (either in one group or in both). As in Doganoglu and Wright (2006) and in Armstrong and Wright (2007), a sensible way to endogenize the choice between single-homing and multi-homing is to let the platform owner offer exclusive contracts, which compel agents accepting such contracts to single-home. In the absence of exclusive contracts, one can conjecture that 
multi-homing makes entry harder for the new platform; however, exclusive contracts might facilitate divide-and-conquer strategies. We leave it to future research to confirm or invalidate this intuition.

\section{Appendices}

\subsection{Proof of Proposition 3}

As for stages 3 and 4 of the game, we can use Lemma 1: all independent agents make the same decision and the intermediary decides to attract them all as long as he has attracted at least half of the rival agents beforehand; that is,

$$
n_{i}^{*}\left(n_{r}\right)= \begin{cases}N_{i} & \text { if } n_{r} \geq N_{r} / 2 \\ 0 & \text { otherwise }\end{cases}
$$

In stage 2, an equilibrium with $0<n_{r}<N_{r}$ agents switching occurs if and only if

$$
\left\{\begin{array}{l}
\pi_{r}\left(n_{r}, n_{i}^{*}\left(n_{r}\right)\right)-A_{r} \geq \pi_{r}\left(N_{r}-n_{r}+1, N_{i}-n_{i}^{*}\left(n_{r}-1\right)\right), \\
\pi_{r}\left(N_{r}-n_{r}, N_{i}-n_{i}^{*}\left(n_{r}\right)\right)>\pi_{r}\left(n_{r}+1, n_{i}^{*}\left(n_{r}+1\right)\right)-A_{r} .
\end{array}\right.
$$

- For $0<n_{r}<\frac{N_{r}}{2}-1, n_{i}^{*}\left(n_{r}-1\right)=n_{i}^{*}\left(n_{r}\right)=n_{i}^{*}\left(n_{r}+1\right)=0$ and the two inequalities become:

$$
-\pi_{r}\left(N_{r}-n_{r}, N_{i}\right)<A_{r} \leq-\pi_{r}\left(N_{r}-n_{r}+1, N_{i}\right) .
$$

As no independent agent will switch afterwards, the intermediary has to pay a subsidy to the rival agents he wants to attract; clearly, such an equilibrium induces losses for the intermediary.

- For $n_{r}=\frac{N_{r}}{2}-1, n_{i}^{*}\left(n_{r}-1\right)=n_{i}^{*}\left(n_{r}\right)=0, n_{i}^{*}\left(n_{r}+1\right)=N_{i}$ and the two inequalities become

$$
\pi_{r}\left(\frac{N_{r}}{2}, N_{i}\right)-\pi_{r}\left(\frac{N_{r}}{2}+1, N_{i}\right)<A_{r} \leq-\pi_{r}\left(\frac{N_{r}}{2}+2, N_{i}\right),
$$

which are clearly incompatible as the left-hand side is positive. No such equilibrium is possible because the intermediary has to subsidize the $\left(\frac{N_{r}}{2}-1\right)$ th rival agent to induce her to switch, but by doing do, 
he also attracts the $\frac{N_{r}}{2}$ th agent who is willing to pay a positive fee to interact with all independent agents on the new platform.

- For $n_{r}=\frac{N_{r}}{2}, n_{i}^{*}\left(n_{r}-1\right)=0, n_{i}^{*}\left(n_{r}\right)=n_{i}^{*}\left(n_{r}+1\right)=N_{i}$ and the two inequalities become

$$
\pi_{r}\left(\frac{N_{r}}{2}+1, N_{i}\right)<A_{r} \leq \pi_{r}\left(\frac{N_{r}}{2}, N_{i}\right)-\pi_{r}\left(\frac{N_{r}}{2}+1, N_{i}\right)
$$

which supposes that $\pi_{r}\left(\frac{N_{r}}{2}, N_{i}\right)>2 \pi_{r}\left(\frac{N_{r}}{2}+1, N_{i}\right)$.

- For $\frac{N_{r}}{2}<n_{r}<N_{r}, n_{i}^{*}\left(n_{r}-1\right)=n_{i}^{*}\left(n_{r}\right)=n_{i}^{*}\left(n_{r}+1\right)=N_{i}$ and the two inequalities become

$$
\pi_{r}\left(n_{r}+1, N_{i}\right)<A_{r} \leq \pi_{r}\left(n_{r}, N_{i}\right)
$$

As no independent agent stays on the existing platform, the intermediary can charge a positive fee to the rival agents he wants to attract. Such equilibria may then be profitable for the intermediary.

Applying the same logic, the equilibrium would involve no rival agent switching $\left(n_{r}=0\right)$ if and only if $A_{r}>-\pi_{r}\left(N_{r}, N_{i}\right)$, and all rival agents switching $\left(n_{r}=N_{r}\right)$ if and only if $A_{r} \leq \pi_{r}\left(N_{r}, N_{i}\right)$.

We can now move to stage 1 where the intermediary has to find the highest value of $A_{r}$ inducing a unique and profitable equilibrium in stage 2. To eliminate the unprofitable equilibrium with $n_{r}=0$, we need to have $A_{r} \leq-\pi_{r}\left(N_{r}, N_{i}\right)$. Such a subsidy also eliminates all equilibria with $\frac{N_{r}}{2} \leq$

$n_{r}<N_{r}$. The remaining equilibria are those with $0<n_{r}<\frac{N_{r}}{2}-1$ and the one with $n_{r}=N_{r}$. The former equilibria are clearly non profitable as a subsidy has to be paid to the $n_{r}$ rival agents while no independent agent will follow. To eliminate the latter equilibria, we take the most stringent condition, which is obtained for $n_{r}=\frac{N_{r}}{2}-2$ as $\pi_{r}$ decreases in its first argument; hence, we need to impose $A_{r} \leq-\pi_{r}\left(\frac{N_{r}}{2}+2, N_{i}\right)$. Under this condition, the unique equilibrium is $n_{r}=N_{r}$. This proves the proposition.

\subsection{Proof of Proposition 4}

Stages 3 and 4 have already been developed in the text. We still need to analyze stages 1 and 2. Moving to stage 2, we first show that there is 
no equilibrium where the independent group is partitioned between the two platforms. An equilibrium with $0<n_{i}<N_{i}$ would require:

$$
\left\{\begin{array}{l}
A_{i} \leq \pi_{i}\left(n_{r}^{*}\left(n_{i}\right)\right)-\pi_{i}\left(N_{r}-n_{r}^{*}\left(n_{i}-1\right)\right) \equiv \bar{A}_{i} \\
A_{i}>\pi_{i}\left(n_{r}^{*}\left(n_{i}+1\right)\right)-\pi_{i}\left(N_{r}-n_{r}^{*}\left(n_{i}\right)\right) \equiv \underline{A}_{i} .
\end{array}\right.
$$

For the two inequalities to be compatible, we need $\bar{A}_{i}>\underline{A}_{i}$ or

$$
\pi_{i}\left(N_{r}-n_{r}^{*}\left(n_{i}\right)\right)-\pi_{i}\left(N_{r}-n_{r}^{*}\left(n_{i}-1\right)\right)>\pi_{i}\left(n_{r}^{*}\left(n_{i}+1\right)\right)-\pi_{i}\left(n_{r}^{*}\left(n_{i}\right)\right) .
$$

The right-hand side is non-negative as, from Assumption 1, $n_{r}^{*}\left(n_{i}+1\right) \geq$ $n_{r}^{*}\left(n_{i}\right)$ and $\pi_{i}$ is an increasing function; by the same token, the left-hand side is non-positive. We thus have a contradiction, which proves our result.

It follows that the two potential equilibria at stage 2 are: $n_{i}=0$ if and only if $A_{i}>\pi_{i}\left(n_{r}^{*}(1)\right)-\pi_{i}\left(N_{r}\right)$, and $n_{i}=N_{i}$ if and only if $A_{i} \leq$ $\pi_{i}\left(n_{r}^{*}\left(N_{i}\right)\right)-\pi_{i}\left(N_{r}-n_{r}^{*}\left(N_{i}-1\right)\right)$.

In stage 1 , we require unique implementation of the (potentially) profitable equilibrium, i.e., $n_{i}=N_{i}$. Therefore, we need $A_{i} \leq \pi_{i}\left(n_{r}^{*}\left(N_{i}\right)\right)-$ $\pi_{i}\left(N_{r}-n_{r}^{*}\left(N_{i}-1\right)\right)$, so that $n_{i}^{*}=N_{i}$ is an equilibrium, and $A_{i} \leq \pi_{i}\left(n_{r}^{*}(1)\right)-$ $\pi_{i}\left(N_{r}\right)$, so that $n_{i}^{*}=0$ is not an equilibrium. Using Assumption 1, we can establish that the latter condition is more stringent than the former. Indeed,

$$
\begin{aligned}
\pi_{i}\left(n_{r}^{*}(1)\right)-\pi_{i}\left(N_{r}\right) & <\pi_{i}\left(n_{r}^{*}\left(N_{i}\right)\right)-\pi_{i}\left(N_{r}-n_{r}^{*}\left(N_{i}-1\right)\right) \Longleftrightarrow \\
\pi_{i}\left(n_{r}^{*}(1)\right)-\pi_{i}\left(n_{r}^{*}\left(N_{i}\right)\right) & <\pi_{i}\left(N_{r}\right)-\pi_{i}\left(N_{r}-n_{r}^{*}\left(N_{i}-1\right)\right),
\end{aligned}
$$

where the left-hand side is non-positive and the right-hand side, non-negative.

\subsection{Rivalry in both groups}

We suppose here that rivalry prevails in both groups of agents. The generic benefit functions are thus $\pi_{1}\left(n_{1}, n_{2}\right)$ and $\pi_{2}\left(n_{1}, n_{2}\right)$. Because of the multiple sources of externalities, it is not surprising that the analysis becomes rather intricate and that almost no general insight can be drawn when using generic benefit functions. Let us briefly show why.

In the sequential switching game, stages 3 and 4 are as in the rivalry case with rivalry in the second group. That is, stage 4 defines the decreasing 
"demand function" $a_{2}\left(n_{1}, n_{2}\right)$ for the new platform, and the intermediary maximizes $n_{2} a_{2}\left(n_{1}, n_{2}\right)$ in stage 3 . This determines a unique maximum, $n_{2}^{*}\left(n_{1}\right)$, which is non-decreasing in $n_{1}$ (under Assumption 1). Moving now to stage $\mathbf{2}$, an equilibrium with $0<n_{1}<N_{1}$ requires:

$$
\left\{\begin{array}{l}
\pi_{1}\left(n_{1}, n_{2}^{*}\left(n_{1}\right)\right)-A_{1} \geq \pi_{1}\left(N_{1}-n_{1}+1, N_{2}-n_{2}^{*}\left(n_{1}-1\right)\right), \\
\pi_{1}\left(N_{1}-n_{1}, N_{2}-n_{2}^{*}\left(n_{1}\right)\right)>\pi_{1}\left(n_{1}+1, n_{2}^{*}\left(n_{1}+1\right)\right)-A_{1} .
\end{array}\right.
$$

Defining

$$
a_{1}\left(n_{1}\right) \equiv \pi_{1}\left(n_{1}, n_{2}^{*}\left(n_{1}\right)\right)-\pi_{1}\left(N_{1}-n_{1}+1, N_{2}-n_{2}^{*}\left(n_{1}-1\right)\right),
$$

we can rewrite the previous two conditions as $a_{1}\left(n_{1}+1\right)<A_{1} \leq a_{1}\left(n_{1}\right)$. The problem here is that there is no guarantee that these two inequalities define an open interval. Indeed, an increase in $n_{1}$ has two contrasting effects on $a_{1}\left(n_{1}\right)$. On the one hand, there is a direct negative effect stemming from the rivalry among agents of group 1: as $n_{1}$ increases, $\pi_{1}\left(n_{1},.\right)$ decreases and $\pi_{1}\left(N_{1}-n_{1}+1,.\right)$ increases, making $a_{1}$ decrease. On the other hand, there is a positive indirect effect through the increase in the number of agents of group 2 who will be attracted subsequently: as $n_{1}$ increases, so do $n_{2}^{*}\left(n_{1}\right)$ and $n_{2}^{*}\left(n_{1}-1\right)$, making $\pi_{1}\left(., n_{2}^{*}\left(n_{1}\right)\right)$ increase, $\pi_{1}\left(., N_{2}-n_{2}^{*}\left(n_{1}-1\right)\right)$ decrease, and so $a_{1}$ increase (at least weakly). In other words, we do not know whether $a_{1}\left(n_{1}\right)$ corresponds to a decreasing demand function for the new platform and, hence, we are unable to solve the first two stages of the game.

In the simultaneous switching game, any partition of the two groups of firms can now emerge at equilibrium. There are thus nine possible equilibrium configurations. As we cannot balance the effect of the conflicting inter- and intra-group externalities, we cannot either delineate the areas in the $\left(A_{1}, A_{2}\right)$ plane for which each possible equilibrium obtains; in particular, we cannot identify precisely the areas with multiple equilibria and, therefore, we cannot express the conditions for unique implementation. Worse, specific profit functions do not really help as it appears that there exist combinations of fees for which there are mutliple equilibria with positive participation of both groups to the new platform. 


\subsection{Applications}

\subsubsection{Linear specifications}

When rival agents move second in the sequential game, the function $n_{r}^{*}\left(n_{i}\right)$ is found as the maximum of

$$
n_{r} a_{r}\left(n_{r}, n_{i}\right)=n_{r}\left(\alpha_{r} n_{i}-\mu n_{r}-\left(\alpha_{r}\left(N_{i}-n_{i}\right)-\mu\left(N_{r}-n_{r}+1\right)\right)\right)
$$

subject to $0 \leq n_{r} \leq N_{r}$. The unconstrained maximum is

$$
n_{r}\left(n_{i}\right)=\frac{1}{4} \frac{\alpha_{r}}{\mu}\left(2 n_{i}-N_{i}\right)+\frac{N_{r}+1}{4}
$$

It can be checked that, under $\mu N_{r}<\alpha_{r}$ and $N_{i} \geq 4, n_{r}(1)<0$ and $n_{r}\left(N_{i}\right)>$ $N_{r}$. Thus, the constrained optima are $n_{r}^{*}(1)=0$ and $n_{r}^{*}\left(N_{i}\right)=N_{r}$.

When the intermediary subsidizes rival agents in the simultaneous game, his problem is to choose $1 \leq x \leq N_{r} / 2$ that maximizes

$$
\Pi_{I}^{s r}(x) \equiv-N_{r}\left(\alpha_{r} N_{i}-\mu x\right)+N_{i}\left(\alpha_{i}\left(N_{r}-x+1\right)-\alpha_{i}(x-1)\right)
$$

It is readily checked that $\Pi_{I}^{s r}(x)$ is an increasing function of $x$ if and only if $\mu N_{r}>2 \alpha_{i} N_{i}$. In that case, $x^{*}=N_{r} / 2$, which yields $\Pi_{I}^{s r}\left(x^{*}\right)<0$ : entry is not profitable in the simultaneous game in which rival agents are subsidized. In the main text, we focus instead on profitable entry which requires the assumption that $\mu N_{r}<2 \alpha_{i} N_{i}$. Then $\Pi_{I}^{s r}(x)$ is decreasing in $x$ and $x^{*}=1$. It follows that

$$
\beta_{i f}=\gamma_{s i}<\beta_{r f}<\gamma_{s r}
$$

where

$\gamma_{s i}=N_{r}\left(\alpha_{r} N_{i}-\mu N_{r}\right), \beta_{r f}=N_{r}\left[\alpha_{r} N_{i}-\mu\left(\frac{N_{r}}{2}+2\right)\right], \gamma_{s r}=N_{r}\left(\alpha_{r} N_{i}-\mu\right)$

Simple computations establish the following equivalences:

$$
\begin{aligned}
& N_{i} \pi_{i}\left(N_{r}\right)>\beta_{i f}=\gamma_{s i} \Longleftrightarrow \mu>\frac{N_{i}}{N_{r}}\left(\alpha_{r}-\alpha_{i}\right), \\
& N_{i} \pi_{i}\left(N_{r}\right)>\beta_{r f} \Longleftrightarrow \mu>\frac{2 N_{i}}{N_{r}+4}\left(\alpha_{r}-\alpha_{i}\right), \\
& N_{i} \pi_{i}\left(N_{r}\right)>\gamma_{s r} \Longleftrightarrow \mu>N_{i}\left(\alpha_{r}-\alpha_{i}\right) .
\end{aligned}
$$




\subsubsection{Successive oligopoly}

We use the benefit functions derived in the main text and we focus on $N_{r} \geq 4$ and $N_{s} \geq 4$. We first consider the sequential switching. It is easy to compute

$$
N_{r} \pi_{r}\left(N_{i}, N_{r}\right)=\frac{N_{r} N_{i}}{2\left(N_{r}+1\right)^{2}}<\beta_{r f}=\frac{2 N_{r} N_{i}}{\left(N_{r}+6\right)^{2}}<N_{i} \pi_{i}\left(N_{r}\right)=\frac{N_{i} N_{r}^{2}}{4\left(N_{r}+1\right)^{2}}
$$

To compute $\beta_{i f}$ we need to evaluate $n_{r}^{*}\left(N_{i}\right)$ and $n_{r}^{*}(1)$. The first expression is easy to find as $n_{r}^{*}\left(N_{i}\right)$ maximizes $n_{r} \pi_{r}\left(n_{i}, n_{r}\right)$, the total profits of rival agents. It is well known that the total profits are maximized under monopoly, $n_{r}^{*}\left(N_{i}\right)=1$. The second expression is found by maximizing $n_{r} \pi_{r}\left(1, n_{r}\right)-n_{r} \pi_{r}\left(N_{i}-1, N_{r}-n_{r}+1\right)$. Simple computations show that both terms decrease with $n_{r}$ if $n_{r}>1$. Hence, there are two possible optima, $n_{r}^{*}(1) \in\{0,1\}$. A few computations show that

$$
n_{r}^{*}(1)=\left\{\begin{array}{ll}
0 \\
1
\end{array} \text { and } \beta_{i f}=\left\{\begin{array}{cl}
\frac{1}{8} N_{i} & \text { if } \quad 4 N_{i}>N_{r}^{2}+2 N_{r}+5, \\
\frac{3}{16} N_{i} & \text { if } \quad 4 N_{i} \leq N_{r}^{2}+2 N_{r}+5 .
\end{array}\right.\right.
$$

In both cases, one can easily check that $\beta_{r f}<\beta_{i f}$. Also, one can check that in general, $N_{i} \pi_{i}\left(N_{r}\right)>\beta_{i f} .{ }^{16}$ This implies that the intermediary does not make profit when he attracts buyers first. ${ }^{17}$

Next, we consider the simultaneous switching. We evaluate

$$
\gamma_{s i}=\frac{1}{8} N_{i}
$$

and we check that $N_{i} \pi_{i}\left(N_{r}\right)>\gamma_{s i}$. Thus the intermediary cannot enter profitably by subsidizing buyers. To check whether he can enter profitably by subsidizing sellers, one could compute $\gamma_{s r}$. However, it is a difficult task to compute $x^{*}$. Still one can show that the intermediary's profits are negative for any $1 \leq x<N_{r} / 2$, which proves that $N_{i} \pi_{i}\left(N_{r}\right)-\gamma_{s r}<0$. Indeed, the intermediary chooses the value of $x$ that maximizes

$$
\Pi_{I}^{s r}=-\frac{N_{r} N_{i}}{2(x+1)^{2}}+N_{i}\left[\frac{\left(N_{r}-x+1\right)^{2}}{4\left(N_{r}-x+2\right)^{2}}-\frac{(x-1)^{2}}{4 x^{2}}\right] .
$$

\footnotetext{
${ }^{16}$ This claim is reversed only if $4 N_{i} \leq N_{r}^{2}+2 N_{r}+5$ and $N_{r} \in\{4,5,6\}$.

${ }^{17}$ In the special case where $4 N_{i} \leq N_{r}^{2}+2 N_{r}+5$ and $N_{r} \in\{4,5,6\}$, the intermediary makes profit when he attracts buyers first, but it can be shown that this profit is smaller than the profit he makes when he attracts sellers first.
} 
In the second term, $\left(N_{r}-x+1\right)^{2} /\left(N_{r}-x+2\right)^{2}<1$. Therefore,

$$
\Pi_{I}^{s r}<-\frac{N_{r} N_{i}}{2(x+1)^{2}}+N_{i}\left[\frac{1}{4}-\frac{(x-1)^{2}}{4 x^{2}}\right]=-\frac{2 x^{2}\left(N_{r}-2 x\right)+(2 x+1)(x-1)^{2}}{4(x+1)^{2} x^{2}}<0
$$

Hence, $\Pi_{I}^{s r}<0$ and $N_{i} \pi_{i}\left(N_{r}\right)<\gamma_{s r}$.

\section{References}

[1] Amir, R. (2003). Market structure, scale economies and industry performance. CORE Discussion Paper 2003/65. Université Catholique de Louvain, Belgium.

[2] Anderson, R.M., Ellison, G., and Fudenberg, D. (2005). Location choice in two-sided markets with indivisible agents. Mimeo, Harvard Institute of Economic Research.

[3] Armstrong, M. (2005). Competition in two-sided markets. Mimeo, Nuffield College, Oxford (forthcoming in Rand Journal of Economics).

[4] Armstrong, M., and Wright, J. (2007). Two-sided markets, competitive bottlenecks and exclusive contracts. Economic Theory (forthcoming).

[5] Baye, M.R., and Morgan J. (2001). Information gatekeepers on the Internet and the competitiveness of homogeneous product markets. American Economic Review 91: 454-474.

[6] Caillaud, B., and Jullien B. (2003). Chicken and egg: Competition among intermediation service providers. RAND Journal of Economics 34: 309-328.

[7] Clements, M.T., and Ohashi, H. (2005). Indirect network effects and the product cycle: Video games in the U.S., 1994-2002. Journal of Industrial Economics 53: 515-542.

[8] Doganoglu, T., and Wright, J. (2006). Exclusive dealing with network effects. Mimeo, National University of Singapore.

[9] Ellison, G., and Fudenberg, D. (2003). Knife-edge or plateau: When do market models tip. Quarterly Journal of Economics 118: 1249-1278. 
[10] Evans, D.J. (2003). The antitrust economics of multi-sided platform markets. Yale Journal on Regulation 20: 325-381.

[11] Evans, D.J., Hagiu, A., and Schmalensee, R. (2005). A survey of the economic role of software platforms in computer-based industries. CES ifo Economic Studies 51:189-224.

[12] Ferrando, J., Gabszewicz, J.J., Laussel, D., and Sonnac, N. (2004). Two-sided network effects and competition: An application to media industries. Mimeo.

[13] Genicot, G., and Ray, D. (2006). Contracts and externalities: How things fall apart. Journal of Economic Theory, 127: 71-100.

[14] Hagiu, A. (2004). Optimal pricing and commitment in two-sided markets. Mimeo (forthcoming in Rand Journal of Economics).

[15] Jullien,B (2005). Two-sided markets and electronic intermediaries. CES ifo Economic Studies 51:235-262.

[16] Jullien, B. (2006). Multi-sided markets: competing with network externalities and price discrimination. Mimeo. University of Toulouse.

[17] Nocke, V., Peitz, M., and Stahl, K. (2004). Platform ownership. Mimeo. University of Manheim, Germany.

[18] Owan, H., and Nickerson, J.A. (2004). Internet exchange formation and competition when potential participants can coordinate. Mimeo. Washington University in St. Louis.

[19] Rasmusen, E.B., Ramseyer, J.M., and Wiley, J.S. Jr (1991). Naked Exclusion. American Economic Review 81: 1137-45.

[20] Rochet, J.-C., and Tirole, J. (2002). Cooperation among competitors: Some economics of payment card associations. RAND Journal of Economics 33: 549-570.

[21] Rochet, J.-C., and Tirole, J. (2003). Platform competition in two-sided markets. Journal of the European Economic Association 1: 990-1029. 
[22] Rochet, J.-C., and Tirole, J. (2005). Two-sided markets: A progress report. Mimeo. IDEI, Toulouse (forthcoming in Rand Journal of Economics).

[23] Segal, I. (2003). Coordination and discrimination in contracting with externalities: divide and conquer? Journal of Economic Theory 113: $147-181$.

[24] Segal, I., and Whinston, M. (2000). Naked Exclusion: Comment. American Economic Review 90: 296-309.

[25] Wright, J. (2003). Optimal card payment systems. European Economic Review 47: 587-612.

[26] Wright, J. (2004). The determinants of optimal interchange fees in payment systems. Journal of Industrial Economics 52: 1-26. 